\title{
Natural Occurring Radioactive Materials (NORM) in the oil and gas industry
}

\section{Jamal Abdul Rahman Zaidan \\ Petroleum Research\& Development Centre}

\section{ABSTRACT}

Radioactive materials which occur naturally and expose people to radiation occur widely, and are known by the acronym 'NORM'. Exposure to NORM is often increased by human activities, eg burning coal, making and using fertilisers, oil and gas production.

Many natural materials contain radioactive elements (radionuclides). The earth's crust is radioactive and constantly leaks radon gas into our atmosphere. However, while the level of individual exposure from all this is usually trivial, some issues arise regarding regulation, and also perspective in relation to what is classified as radioactive waste.The radionuclides identified in oil and gas streams belong to the decay chains of the naturally occurring primordial radionuclides 238U and 232Th. Analyses of NORM from many different oil and gas fields show that the solids found in the downhole and surface structures of oil and gas production facilities do not include 238U and 232Th. gas

These elements are not mobilized from the reservoir rock that contains the oil, gas and formation water.

Formation water contains the radium isotopes 226Ra from the 238U series, and 228Ra and 224Ra from the 232Th series. All three radium isotopes, but not their parents, thus appear in the water co-produced with the oil or gas. The $228 \mathrm{Th}$ radionuclide sometimes detected in aged sludge. This causes their precipitation as sulphate and carbonate scales. The mixed stream of oil, and water also carries the noble gas 222Rn that is generated in the reservoir rock through decay of 226Ra. It would appear that the concentrations of 226Ra, 228Ra and 224Ra in scales and sludge range from less than 0.1 $\mathrm{Bq} / \mathrm{g}$ up to $15000 \mathrm{~Bq} / \mathrm{g}$. Generally, the activity concentrations of radium isotopes are lower in sludge than in scales, the opposite applies to $210 \mathrm{~Pb}$. The deposition of contaminated scales and sludge in pipes and vessels may produce significant dose rates inside and outside these components. Maximum dose rates are usually in the range of up to a few microsieverts per hour. In exceptional cases, dose rates measured directly on the outside surfaces of production equipment have reached several hundred microsieverts per hour, which is about 1000 times greater than normal background values due to cosmic radiation and terrestrial radiation.

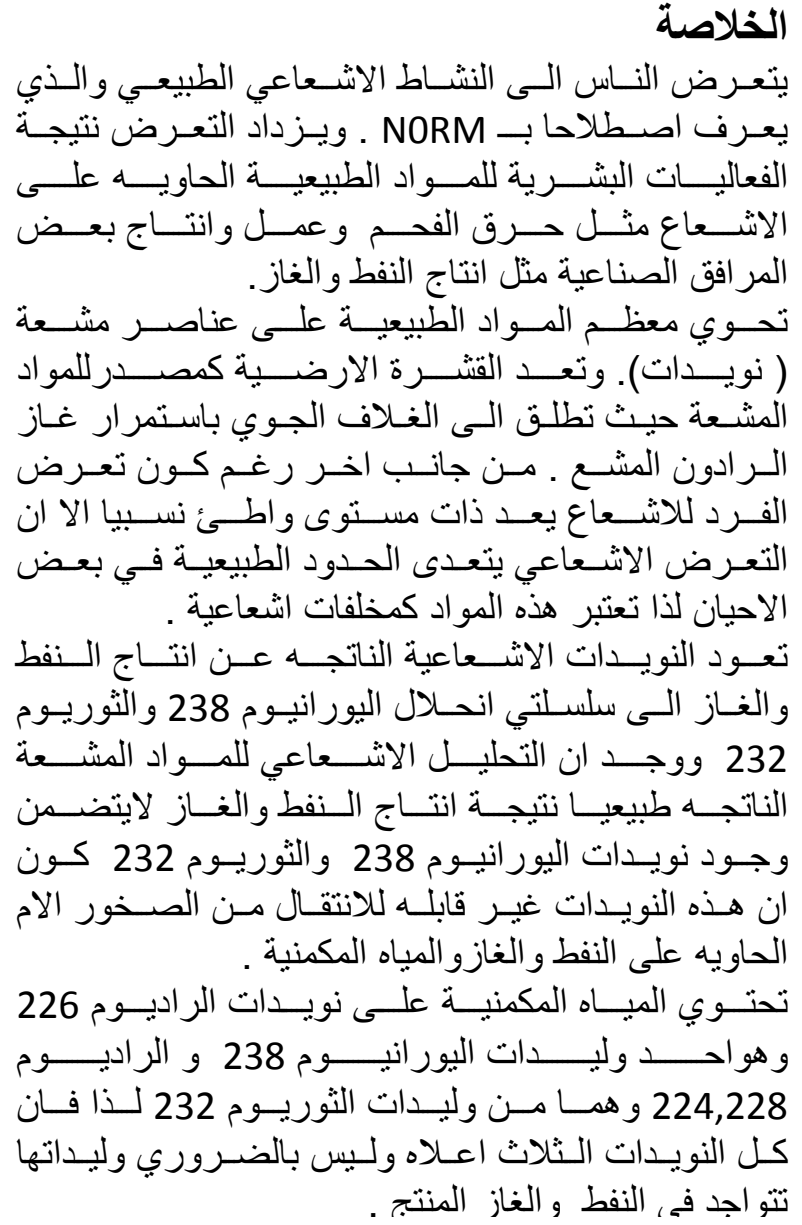




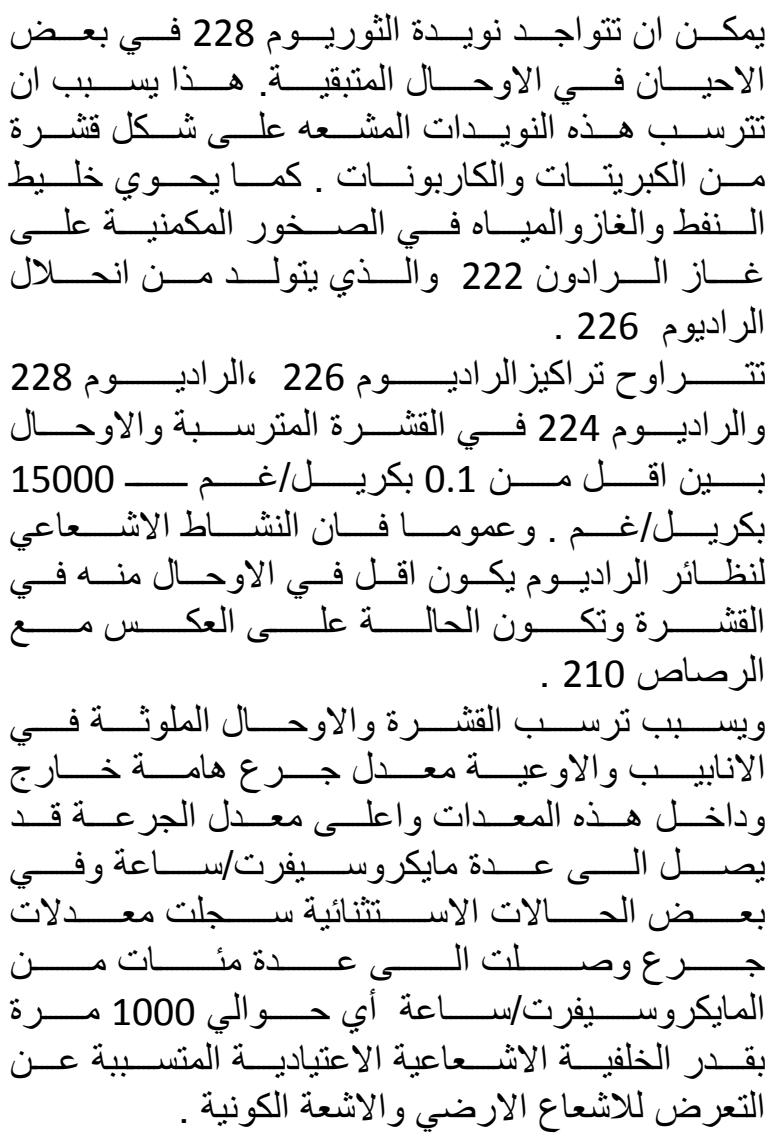

\section{INTRODUCTION}

Radioactive materials, sealed sources and radiation generators are used extensively by the oil and gas industry, and various solid and liquid wastes containing naturally occurring radioactive material (NORM) are produced.

The presence of these radioactive materials and radiation generators results in the need to control occupational and public exposures to ionizing radiation.

Various radioactive wastes are produced in the oil and gas industry, including the following:

(a) Discrete sealed sources, e.g., spent and disused sealed sources;

(b) Unsealed sources, e.g., tracers;

(c) Contaminated items;

(d) Wastes arising from decontamination activities ,e.g., scales and sludge.
These wastes are generated predominantly in solid and liquid forms and may contain artificial or naturally occurring radionuclides with a wide range of half-lives.

The oil and gas companies themselves are not experts in every aspect of the technology applied in their industry. Frequently, the necessary expertise is provided to the industry by specialized support

organizations. Obviously, it is in the interests of the oil and gas industry to demonstrate an appropriate standard of basic radiation safety, environmental control and waste management and to have a common understanding of requirements and controls to establish efficient and safe operations.

The international atomic energy agency (IAEA) establishes principles, requirements and guidance with respect to radiation protection and safety in its Safety Standards Series publications, comprising Safety Fundamentals, Safety Requirements and Safety Guides. The Safety Guide on Occupational Radiation Protection [1] provides general guidance on the control of occupational exposures. This guidance is based on the requirements contained in the International Basic Safety Standards for Protection against lonizing Radiation and for the Safety of Radiation Sources (BSS) [2]. The objectives, concepts and principles of radioactive waste management are presented in the Safety Fundamentals publication on The Principles of Radioactive Waste Management [3]. 


\section{ORIGIN AND RADIOLOGICAL CHARACTERISTICS OF NORM}

The NORM Occurs Reservoir rock contains small amounts of natural uranium and thorium and their radioactive daughters. One daughter, radium, is water soluble dissolves in the reservoir water. Radium can precipitate with the barium and calcium ions to make any scales slightly radioactive.

Clay and fine particles can absorb the radium from the formation water.

The radionuclides identified in oil and gas streams belong to the decay chains of the naturally occurring primordial radionuclides $238 \mathrm{U}$ and 232Th. The presence in subsurface formations from which hydrocarbon are produced, these parent radionuclides have very long half-lives and are ubiquitous in the earth's crust with activity concentrations that depend on the type of rock. Radioactive decay of $238 \mathrm{U}$ and 232Th produces several series of daughter radioisotopes of different elements and of different physical characteristics with respect to their half-lives, modes of decay, and types and energies of emitted radiation (Figs 1, 2 and Table I) [4].
Analyses of NORM from many different oil and gas fields show that the solids found in the downhole and surface structures of oil and gas production facilities do not include $238 \mathrm{U}$ and 232Th [5]. These elements are not mobilized from the reservoir rock that contains the oil, gas and formation water (Figs 1and 2).

The formation water contains Group II (Periodic Table) cations of calcium, strontium, barium and radium dissolved from the reservoir rock. As a consequence, formation water contains the radium isotopes 226Ra from the $238 \mathrm{U}$ series (Fig. 1) and 228Ra and 224Ra from the 232Th series (Fig. 2). All three radium isotopes, but not their parents, thus appear in the water coproduced with the oil or gas. They are referred to as 'unsupported' because their long lived parents $238 \mathrm{U}$ and 232Th and also 228Th remain in the reservoir.

The 228Th radionuclide sometimes detected in aged sludge and scale is likely to be present as a product of the decay of the mobilized 228Ra. When the ions of the Group II elements, including radium, are present in the produced water, drops in pressure and temperature can lead to the solubility products of their mixed sulphates and carbonates being exceeded. 


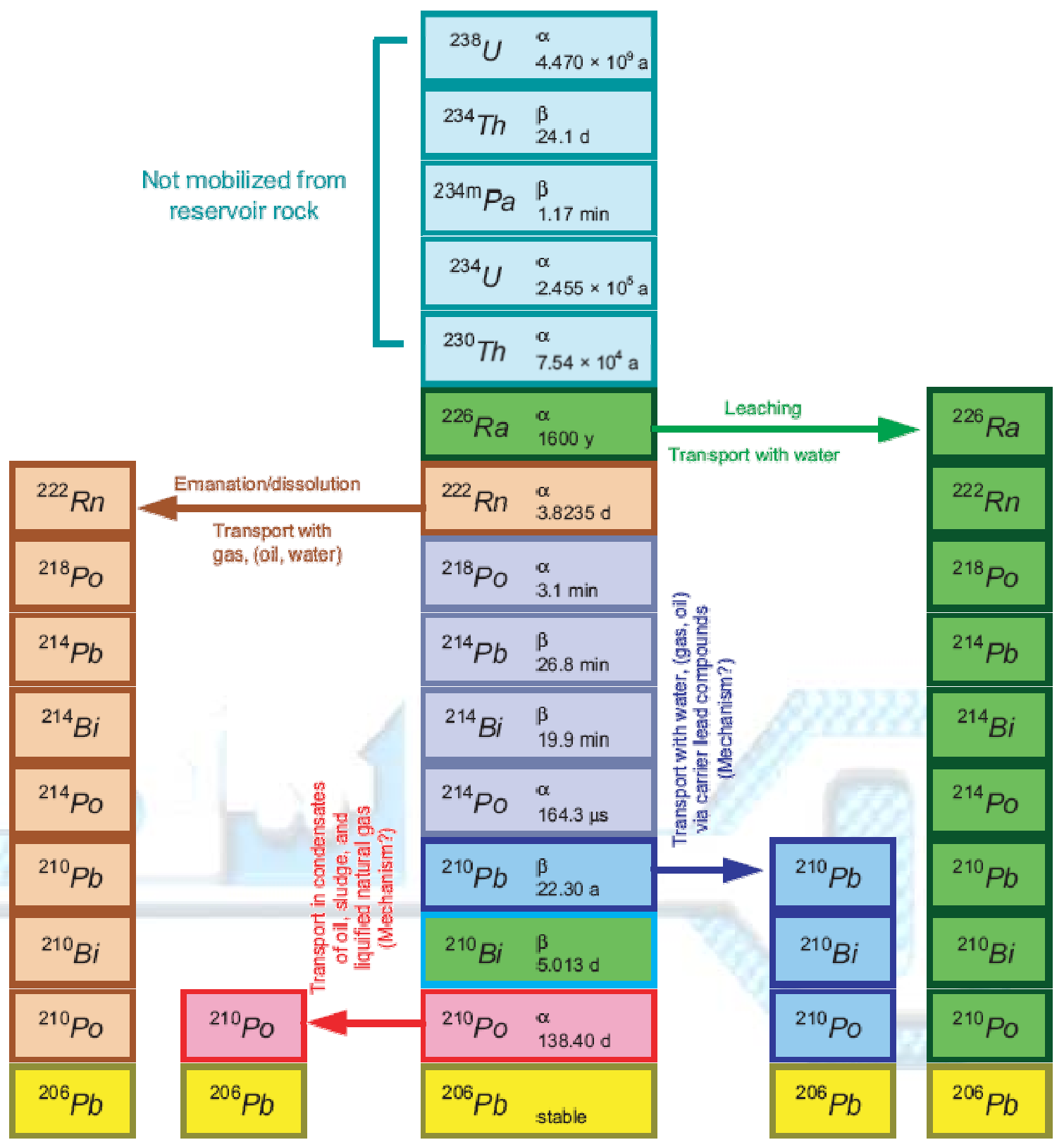

Fig. 1. U-238 decay series

Referring to Fig. 3, this causes their precipitation as sulphate and carbonate scales on the inner walls of production tubulars (T), wellheads (W), valves (V), pumps (P), separators (S), water treatment vessels $(H)$, gas treatment $(\mathrm{G})$ and oil storage tanks (O). Deposition occurs where turbulent opportunities. Particles of clay or sand co-produced which will result in scale deposits in the well completion, or the waters may be combined from different producing wells and mixed in topside plant and equipment. 
flow, centripetal forces and nucleation sites provide the

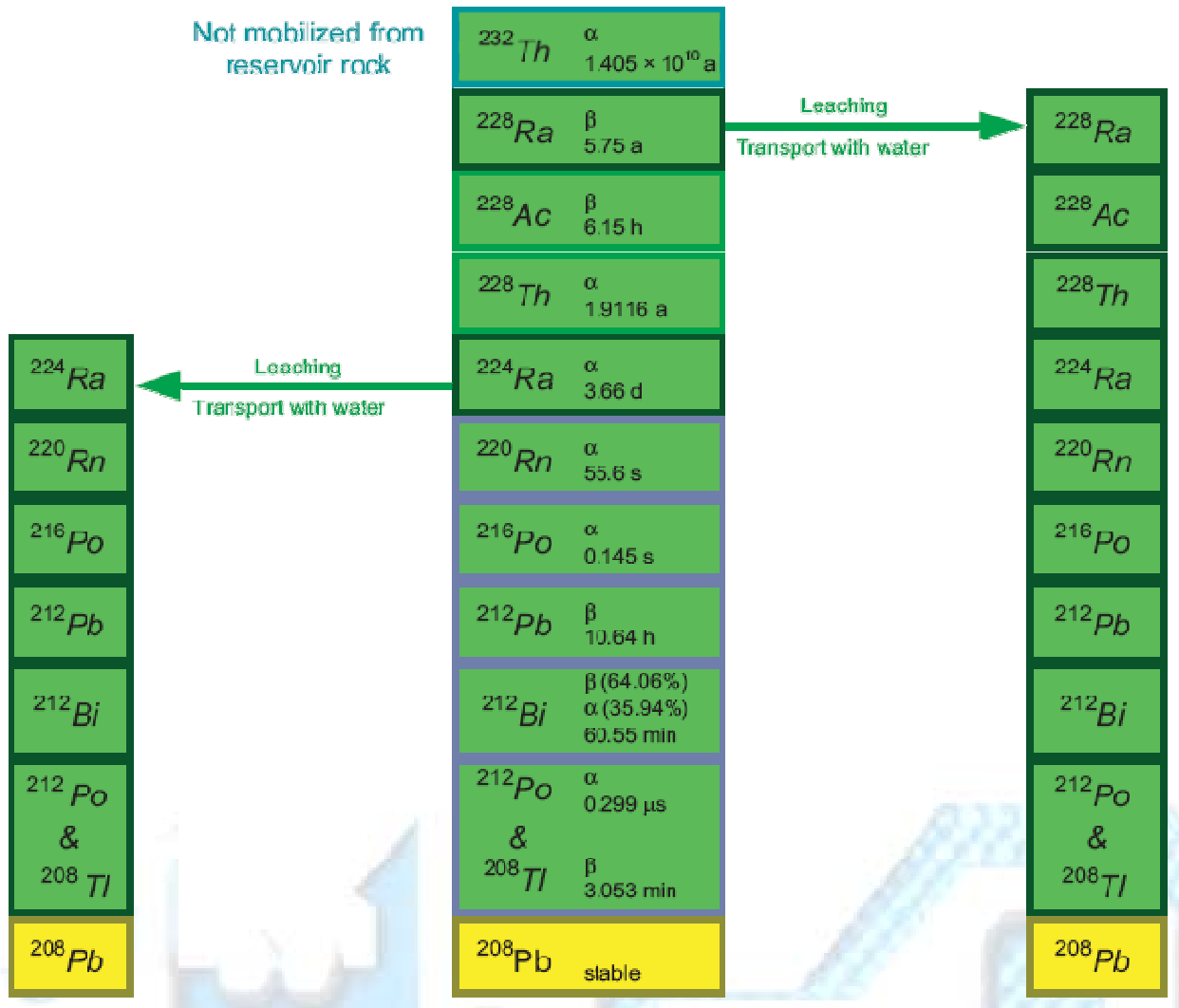

Fig. 2. Th-232 decay series.

Table-1 Radioactive decay characteristics of naturally occurring radionuclides associated with gas and oil production [4]

\begin{tabular}{|c|c|c|c|}
\hline Radionuclide & Half-life & Mode of decay & Main decay product(s) \\
\hline Ra-226 & $1600 \mathrm{a}$ & Alpha & Rn-222(noble gas) \\
\hline Rn-222 & $3.8235 \mathrm{~d}$ & Beta & Short lived progeny \\
\hline Pb-210 & $22.30 \mathrm{a}$ & beta & Po-210 \\
\hline Po-210 & $138.40 \mathrm{~d}$ & Alpha & Pb-206 \\
\hline Ra-228 & $5.75 \mathrm{a}$ & Beta & Th-228 \\
\hline Th-228 & $1.9116 \mathrm{a}$ & Alpha & Ra-224 \\
\hline Ra-224 & $3.66 \mathrm{~d}$ & Alpha & Short lived progeny \\
\hline
\end{tabular}




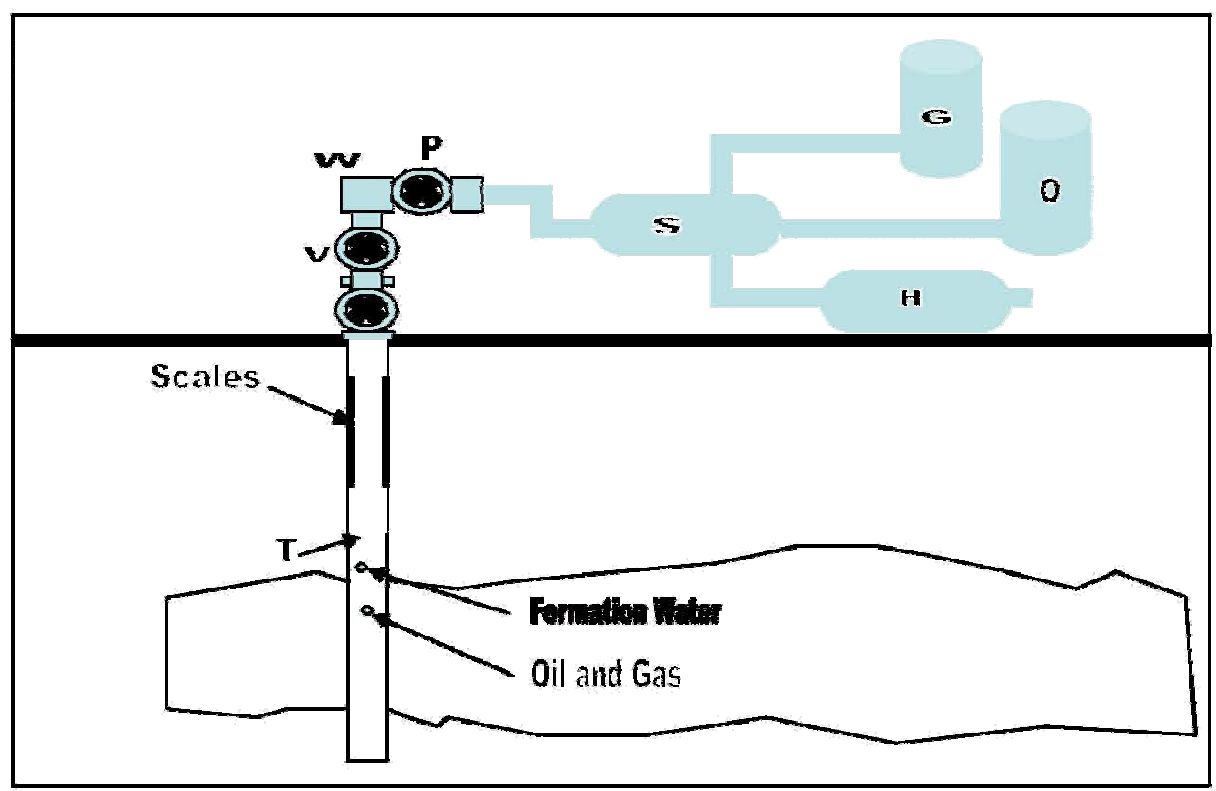

Fig. 3. Precipitation of scales in production plant and equipment

The mixed stream of oil, gas and water also carries the noble gas $222 \mathrm{Rn}$ that is generated in the reservoir rock through decay of 226Ra. This radioactive gas from the production zone travels with the gas-water stream and then follows, preferentially, the dry export gases (Fig. 1). Consequently, equipment from gas treatment and transport facilities may accumulate a very thin film of $210 \mathrm{~Pb}$ formed by the decay of short lived progeny of $222 \mathrm{Rn}$ adhering to the inner surfaces of gas lines. These $210 \mathrm{~Pb}$ deposits are also encountered in liquefied natural gas processing plants $[6,10]$.

A quite different mechanism results in the mobilization, from the

2. MAIN FORMS OF APPEARANCE OF NORM reservoir rock, of stable lead that contains relatively high concentrations of the radionuclide $210 \mathrm{~Pb}$. This mechanism, although not well understood [5], has been observed in a number of gas production fields and results in the deposition of thin, active lead films on the internal surfaces of production equipment and the appearance of stable lead and $210 \mathrm{~Pb}$ in sludge. Condensates, extracted as liquids from natural gas, may contain relatively high levels of $222 \mathrm{Rn}$ and unsupported $210 \mathrm{~Pb}$. In addition, 210Po is observed at levels in excess of its grandparent $210 \mathrm{~Pb}$, indicating direct emanation from the reservoir (Fig. 1).

The main forms of appearance of NORM in oil and gas 
production are summarized in Table- 2.

NORM encountered in oil and gas exploration, development and production operations originates in subsurface formations, which may contain radioactive materials such as uranium and thorium and their daughter products, radium 226 and radium228. NORM can be brought to the surface in the formation water that is produced in conjunction with oil and gas. NORM in these produced waters typically consists of the radionuclides, radium 226 and 228. In addition, radon gas, a radium daughter, may be found in produced natural gas. Because the levels are typically so low, NORM in produced waters and natural gas from wells.

Through temperature and pressure changes that occur in the course of oil and gas production operations, radium 226 and 228 found in produced waters may coprecipitate with barium sulfate scale in well tubulars and surface equipment. Concentrations of radium 226 and 228 may also occur in sludge that accumulates in oilfield pits and tanks. These solids become sources of oil and gas NORM waste. In gas processing activities, NORM generally occurs as radon gas in the natural gas stream. Radon decays to Lead-210, then to Bismuth-210, Polonium-210, and finally to stable Lead-206. Radon decay elements occur as a film on the inner surface of inlet lines, treating units, pumps, and valves principally associated with propylene, ethane, and propane processing streams.

Workers employed in the area of cutting and reaming oil field pipe, removing solids from tanks and pits, and refurbishing gas processing equipment may be exposed to particles containing levels radionuclides that could pose health risks if inhaled or ingested.

An additional type of NORM associated with oil production has been reported recently [11]. Biofouling/corrosion deposits occurring within various parts of seawater injection systems, including injection wells and crosscountry pipelines, have been found to contain significantly enhanced concentrations of uranium originating from the seawater (where it is present in concentrations of a few parts per billion) as a result of the action of sulphate-reducing bacteria under anaerobic conditions.

Scale deposition interferes in the long term with the production process by blocking transport through the pay zone, flow lines and produced water lines, and may interfere with the safe operation of the installation. Operators 
try to prevent deposition of scales through the application of chemical scale inhibitors in the seawater injection system, in the topside equipment located downstream from the wellhead, or in the producing well [12]. To the extent that these chemicals prevent the deposition of the sulphate and carbonate scales, the radium isotopes will pass through the production system and be released with the produced water. Methods of chemical descaling are applied in situ using scale dissolvers when scaling interferes with production and mechanical removal is not the method of choice $[13,14]$.

The extent of mobilization of radionuclides from reservoirs and their appearance in produced water and production equipment varies greatly between installations and between individual wells. In general, heavier scaling is encountered more frequently in oil producing installations than in gas production facilities.

Over the production lifetime, the produced water may become increasingly more saline, indicating the co-production of brine. This may enhance the dissolution of the
Group II elements - including radium - from the reservoir rock in a manner similar to the effect of seawater injection when it is used to enhance recovery. Therefore, over the lifetime of a well, NORM may be virtually absent at first but then start to appear later. The mobilization of lead with $210 \mathrm{~Pb}$ is also variable.

The extent to which sludge is produced and the need to remove it regularly from separators and systems handling produced water also vary strongly between reservoirs, individual wells, installations and production conditions. As a consequence, there are neither typical concentrations of radionuclides in NORM from oil and gas production, nor typical amounts of scales and sludge being produced annually or over the lifetime of a well.

In the separation of natural gas by liquefaction, radon can become concentrated with gases that have similar liquefaction temperatures. It is expected that $210 \mathrm{Po}$ and $210 \mathrm{~Pb}$ would also become concentrated in certain parts of the process [9]. 
Table-2. NORM in oil and gas production

\begin{tabular}{|c|c|c|c|}
\hline Type & Radionuclides & Characteristics & Occurrence \\
\hline Ra scales & $\begin{array}{l}\text { Ra-226, Ra-228, Ra-224 } \\
\text { and their progeny. }\end{array}$ & $\begin{array}{c}\text { Hard deposits of } \mathrm{Ca}, \mathrm{Sr} \text {, } \\
\text { Ba sulphates and } \\
\text { carbonates }\end{array}$ & $\begin{array}{l}\text { Wet parts of production } \\
\text { Installations Well } \\
\text { completions }\end{array}$ \\
\hline Ra sludge & $\begin{array}{l}\text { Ra-226, Ra-228, } \\
\text { Ra-224 and their } \\
\text { progeny }\end{array}$ & $\begin{array}{l}\text { Sand, clay, paraffins, } \\
\text { heavy metals }\end{array}$ & $\begin{array}{c}\text { Separators, skimmer } \\
\text { tanks }\end{array}$ \\
\hline Pb deposits & $\begin{array}{l}\mathrm{Pb}-210 \text { and its } \\
\text { progeny }\end{array}$ & Stable lead deposits & $\begin{array}{l}\text { Wet parts of gas } \\
\text { production } \\
\text { Installations } \\
\text { Well completions }\end{array}$ \\
\hline Pb films & $\begin{array}{l}\mathrm{Pb}-210 \text { and its } \\
\text { progeny }\end{array}$ & Very thin films & $\begin{array}{c}\text { Oil and gas treatment } \\
\text { and } \\
\text { transport }\end{array}$ \\
\hline Po films & Po-210 & Very thin films & $\begin{array}{c}\text { Condensates treatment } \\
\text { facilities }\end{array}$ \\
\hline Condensates & Po-210 & Unsupported & Gas production \\
\hline Natural gas & $\begin{array}{c}\text { Rn-222 } \\
\text { Pb-210, Po-210 }\end{array}$ & $\begin{array}{c}\text { Noble gas } \\
\text { Plated on surfaces }\end{array}$ & $\begin{array}{c}\text { Consumers domain } \\
\text { Gas treatment and } \\
\text { transport } \\
\text { systems }\end{array}$ \\
\hline $\begin{array}{l}\text { Produced } \\
\text { water }\end{array}$ & $\begin{array}{c}\text { Ra-226, Ra-228, } \\
\text { Ra-224 and/or } \\
\text { Pb-210 }\end{array}$ & $\begin{array}{l}\text { More or less saline, } \\
\text { large volumes in oil } \\
\text { production }\end{array}$ & $\begin{array}{l}\text { Each production } \\
\text { facility }\end{array}$ \\
\hline
\end{tabular}

\section{RADIONUCLIDE}

\section{CONCENTRATIONS IN NORM}

A large amount of data has been collected over the years on the radionuclide concentrations in NORM, although relatively few reports have been published. It would appear that the concentrations of 226Ra, 228Ra and 224Ra in scales and sludge range from less than $0.1 \mathrm{~Bq} / \mathrm{g}$ up to 15 $000 \mathrm{~Bq} / \mathrm{g}$ [5] (Table-3).

Generally, the activity concentrations of radium isotopes are lower in sludge than in scales. The opposite applies to 210Pb, which usually has a relatively low concentration in hard scales but which may reach a concentration of more than $1000 \mathrm{~Bq} / \mathrm{g}$ in lead deposits and sludge. Although thorium isotopes are not mobilized from the reservoir, the decay product 228Th starts to grow in from 228Ra after deposition of the latter.

As a result, when scales containing 228Ra grow older, the concentration of 228Th increases to about $150 \%$ of the concentration of 228Ra still present. 
Table- 3. Concentration of NORM in oil and gas products

[5]

\begin{tabular}{|c|c|c|c|c|c|}
\hline Radionuclide & $\begin{array}{c}\text { Crude oil } \\
\text { Bq/g }\end{array}$ & $\begin{array}{l}\text { Natural gas } \\
\mathrm{Bq} / \mathrm{m} 3\end{array}$ & $\begin{array}{c}\text { Produced } \\
\text { water } \mathrm{Bq} / \mathrm{L}\end{array}$ & $\begin{array}{c}\text { Hard scale } \\
\text { Bq/g }\end{array}$ & $\begin{array}{l}\text { Sludge } \\
\mathrm{Bq} / \mathrm{g}\end{array}$ \\
\hline U-238 & $\begin{array}{r}0.0000001- \\
0.01\end{array}$ & & $0.0003-0.1$ & $0.001-0.5$ & $0.005-0.01$ \\
\hline Ra-226 & $0.0001-0.04$ & & $\begin{array}{r}0.002- \\
1200\end{array}$ & $0.1-15$ & $0000.05-800$ \\
\hline Po-210 & $0-0.01$ & $0.002-0.08$ & & $0.02-1.5$ & $0.004-160$ \\
\hline Pb-210 & & $0.005-0.02$ & $0.05-190$ & $0.02-75$ & $0.1-1300$ \\
\hline Rn-222 & & $5-200000$ & & & \\
\hline Th-232 & $\begin{array}{r}0.00003- \\
0.002\end{array}$ & & $\begin{array}{r}0.0003- \\
0.001\end{array}$ & $0.001-0.002$ & $0.002-0.01$ \\
\hline Ra-228 & & & $0.3-180$ & $0.05-2800$ & $0.5-50$ \\
\hline Ra-224 & & & $0.5-40$ & & \\
\hline
\end{tabular}

\section{RADIATION PROTECTION ASPECTS OF NORM}

In the absence of suitable radiation protection measures, NORM in the oil and gas industry could cause external exposure during production owing to accumulations of gamma emitting radionuclides and internal exposures of workers and other persons, particularly during maintenance, the transport of waste and contaminated equipment, the decontamination of equipment, and the processing and disposal of waste. Exposures of a similar nature may also arise during the decommissioning of oil and gas production facilities and their associated waste management facilities.

provided by pipe or vessel walls. Maximum dose rates are usually in the range of up to a few microsieverts per hour. In exceptional cases, dose rates measured directly on the outside surfaces of production equipment have

\subsection{EXTERNAL EXPOSURE}

The deposition of contaminated scales and sludge in pipes and vessels may produce significant dose rates inside and outside these components (Table-4). Short lived progeny of the radium isotopes, in particular 226Ra, emit gamma radiation capable of penetrating the walls of these components, and the high energy photon emitted by 208TI (one of the progeny of 228Th) can contribute significantly to the dose rate on outside surfaces when scale has been accumulating over a period of several months. The dose rates depend on the amount and activity concentrations of the radionuclides present inside and the shielding reached several hundred microsieverts per hour [5, 15], which is about 1000 times greater than normal background values due to cosmic radiation and terrestrial radiation. 
Table- 4. External gamma radiation dose rates observed in some oil production and processing facilities.

\begin{tabular}{|c|c|}
\hline Location & $\begin{array}{l}\text { Dose rate } \\
(\mu \mathrm{Sv} / \mathrm{h})\end{array}$ \\
\hline $\begin{array}{l}\text { Down hole tubing, } \\
\text { safety valves (internal) }\end{array}$ & up to 300 \\
\hline $\begin{array}{l}\text { Wellheads, production } \\
\text { manifold }\end{array}$ & $0.1-22.5$ \\
\hline Production lines & $0.3-4$ \\
\hline $\begin{array}{l}\text { Separator (scale, } \\
\text { measured internally) }\end{array}$ & up to 200 \\
\hline $\begin{array}{l}\text { Separator (scale, } \\
\text { measured externally) }\end{array}$ & up to 15 \\
\hline Water outlets & $0.2-0.5$ \\
\hline
\end{tabular}

The buildup of radium scales can be monitored without opening plant or equipment (Fig. 4). Where scales are present, opening the system for maintenance or for other purposes will increase dose rates. External exposure can be restricted only by maximizing the distance from, and minimizing duration of exposure to, the components involved. In practice, restrictions on access and

\subsection{INTERNAL EXPOSURE}

Internal exposure to NORM may result from the ingestion or inhalation of radionuclides. This may occur while working on or in open plant and equipment, handling waste materials and surface contaminated objects, and during the cleaning of contaminated equipment. Ingestion can also occur if precautions are not taken prior to eating, drinking, occupancy time are found to be effective in limiting annual doses to low values.

Deposits consisting almost exclusively of $210 \mathrm{~Pb}$ cannot be assessed by measurements outside closed plant and equipment. Neither the low energy gamma emissions of $210 \mathrm{~Pb}$ nor the beta particles emitted penetrate the steel walls. Therefore, $210 \mathrm{~Pb}$ does not contribute significantly to external dose and its presence can be assessed only when components are opened

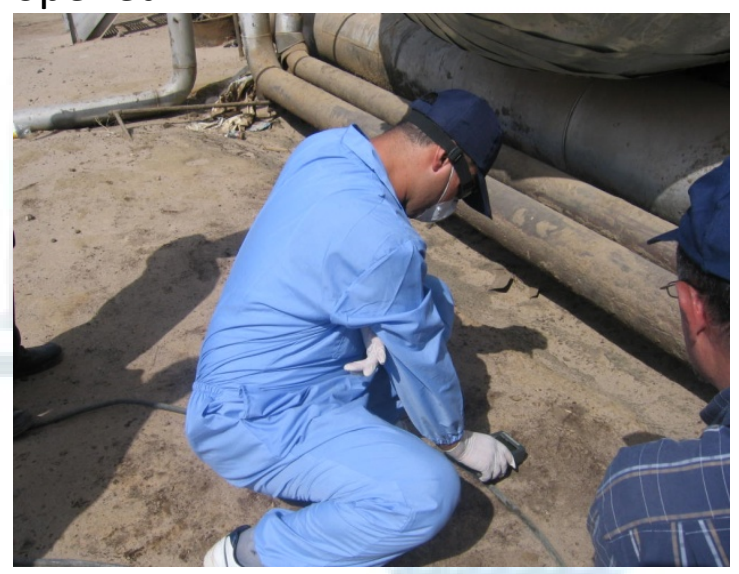

Fig. 4. Monitoring the outside of plant and equipment using a dose rate meter (Basrah, Iraq).

smoking, etc. More detail on this issue is provided in Section 4.4.2.

Effective precautions are needed during the aforementioned operations to contain the radioactive contamination and prevent its transfer to areas where other persons might also be exposed. The non-radioactive characteristics of scales and sludge also demand conventional safety measures, and therefore the risk of 
ingesting NORM is likely to be very low indeed. However, cleaning contaminated surfaces during repair, replacement, refurbishment or other work may generate airborne radioactive material, particularly if dry abrasive techniques are used. The exposure from inhalation could become significant if effective personal protective equipment (including respiratory protection) and/or engineered controls are not used. The potential committed dose from inhalation depends on both the physical and chemical characteristics of NORM. It is important to consider the radionuclide composition and activity concentrations, the activity aerodynamic size distribution of the particles (quantified by the activity median aerodynamic diameter, or AMAD), and the chemical forms of the elements and the corresponding lung absorption types. Table II-V (Schedule II) of the BSS [2] quotes the following lung absorption types for the elements of interest for dose calculations:
(a) Radium (all compounds): medium (M)

(b) Lead (all compounds): fast (F)

(c) Polonium (all unspecified compounds):

fast (F)

(oxides, hydroxides, nitrates): medium (M)

(d) Bismuth (nitrate): fast (F) (all unspecified compounds): medium (M)

(e) Thorium (all unspecified compounds): medium (M) (oxides, hydroxides): slow (S).

Table-5 gives the effective dose per unit intake of dust particles of $5 \mu \mathrm{m}$ AMAD (the default size distribution for normal work situations) and 1 $\mu \mathrm{m}$ AMAD (a size distribution that may be more appropriate for work situations such as those involving the use of high temperature cutting torches). For each case, values are quoted for the slowest lung absorption type listed in the BSS (S for thorium, $M$ for radium, polonium and bismuth, and $F$ for lead - as noted above). In addition, values for $5 \mu \mathrm{m}$ AMAD calculated by Silk [16] are quoted, based on a more conservative assumption that all radionuclides are of lung absorption type $\mathrm{S}$.

Table- 5 indicates that the inhalation of particles of $5 \mu \mathrm{m}$ AMAD incorporating 226Ra (with its complete decay chain in equilibrium), 228Ra, and 224Ra (with its complete decay chain in equilibrium), each at a concentration of $10 \mathrm{~Bq} / \mathrm{g}$, would deliver a committed effective dose per unit intake of about 0.1-1 $\mathrm{mSv} / \mathrm{g}$, the exact value depending on the extent of ingrowth of 228Th from 228Ra and the lung absorption types assumed. For $1 \mu \mathrm{m}$ AMAD particles, the committed effective dose per unit intake would be about $25-30 \%$ higher (based on the slowest lung absorption types listed in the BSS). 
Table- 5. Dose per unit intake for inhalation of radionuclides in particles of

NORM scale.

\begin{tabular}{|c|c|c|c|}
\hline \multirow[b]{3}{*}{ Radionuclide } & \multicolumn{3}{|c|}{ Committed effective dose per unit intake (Sv/Bq) } \\
\hline & \multicolumn{2}{|c|}{$5 \mu \mathrm{m}$ AMAD } & \multirow{2}{*}{$\begin{array}{c}5 \mu \mathrm{m} \text { AMAD } \\
\text { Slowest lung absorption } \\
\text { type listed in BSS [2] }\end{array}$} \\
\hline & $\begin{array}{c}\text { Slowest lung absorption } \\
\text { type listed in BSS [2] }\end{array}$ & $\begin{array}{c}\text { Slow (S) absorption } \\
\text { type [16] }\end{array}$ & \\
\hline Ra-226 & $2.2 \times 10^{-6}$ & $3.8 \times 10^{-5}$ & $3.2 \times 10^{-6}$ \\
\hline $\mathrm{Pb}-210$ & $1.1 \times 10^{-6}$ & $4.5 \times 10^{-6}$ & $8.9 \times 10^{-7}$ \\
\hline Po-210 & $2.2 \times 10^{-6}$ & $2.8 \times 10^{-6}$ & $3.0 \times 10^{-6}$ \\
\hline Ra-228 & $1.7 \times 10^{-6}$ & $1.2 \times 10^{-5}$ & $2.6 \times 10^{-6}$ \\
\hline Th-228 & $3.2 \times 10^{-5}$ & $3.2 \times 10^{-5}$ & $3.9 \times 10^{-5}$ \\
\hline Ra-224 & $2.4 \times 10^{-6}$ & $2.8 \times 10^{-6}$ & $2.9 \times 10^{-6}$ \\
\hline
\end{tabular}

\subsection{DECONTAMINATION OF PLANT AND EQUIPMENT}

The removal of NORMcontaining scales and sludge from plant and equipment, whether for production and safety reasons or during decommissioning, needs to be carried out with adequate radiation protection measures having been taken and with due regard for other relevant safety, waste management and environmental aspects. In addition to the obvious industrial and fire hazards, the presence of other contaminants such as hydrogen sulphide, mercury and hydrocarbons (including benzene) may necessitate the introduction of supplementary safety measures.

On-site decontamination is the method preferred by operators when the accumulation of scales and sludge interferes with the rate and safety of oil and gas production, especially when the components cannot be reasonably removed and replaced or when they need no other treatment before continued use. The work may be carried out by the operator's workers but is usually contracted out to service companies. It will necessitate arrangements, such as the construction of temporary habitats, being made to contain any spillage of hazardous material and to prevent the spread of contamination from the area designated for the decontamination work. Decontamination work has to be performed off the site where:

(a) On-site decontamination cannot be performed effectively and/or in a radiologically safe manner;

(b) The plant or equipment has to be refurbished by specialists prior to reinstallation;

(c) The plant or equipment needs to be decontaminated to allow clearance from regulatory control for purposes of reuse, recycling or disposal as normal waste.

Service companies hired to perform decontamination work 
need to be made fully aware of the potential hazards and the rationale behind the necessary precautions, and may need to be supervised by a qualified person.

The service companies may be able to provide specific facilities and equipment for the safe conduct of the decontamination operations, for example, a converted freight container on the site (Fig.5) or a designated area dedicated to the task (Fig. 6.). Personal protective measures will comprise protective clothing and, in the case of handling dry scale, respiratory protection as well.

The regulatory body needs to set down conditions for the:

(a) Protection of workers, the public and the environment;

(b) Safe disposal of solid wastes;

(c) Discharge of contaminated water;

(d) Conditional or unconditional release of the decontaminated components.

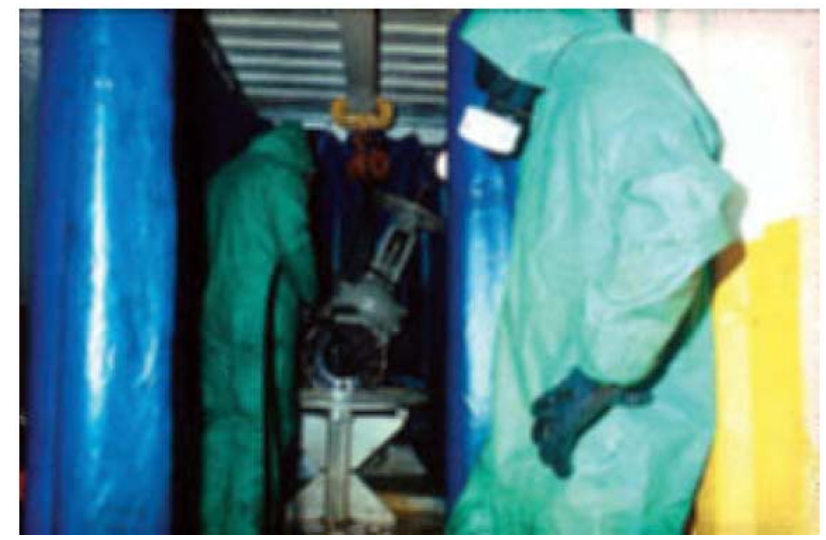

Fig.5. Workers wearing personal protective equipment decontaminating a valve inside an on-site facility.

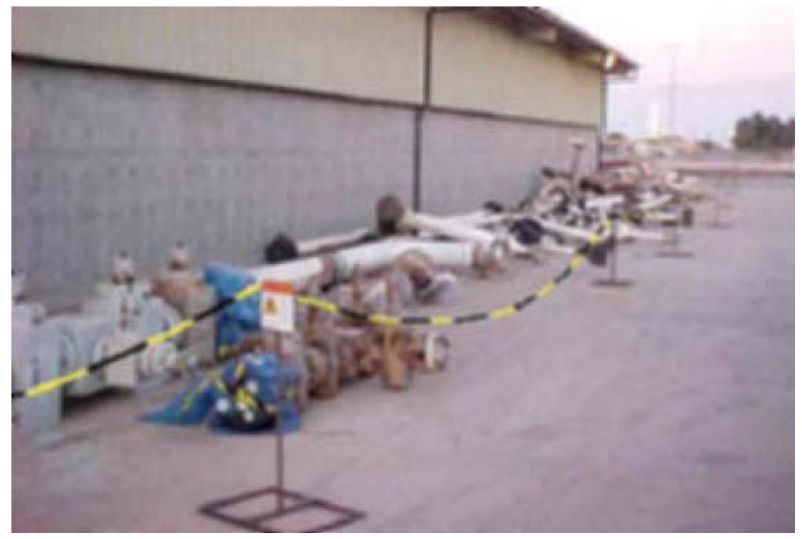

Fig.6. Barrier designating a controlled area to restrict access to NORM-contaminated equipment stored outside a decontamination facility

\subsection{PRACTICAL RADIATION PROTECTION MEASURES}

The requirements for radiation protection and safety established in the BSS [2] apply to NORM associated with installations in the oil and gas industry.

The common goal in all situations is to keep radiation doses as low as reasonably achievable, economic and social factors being taken into account (ALARA), and below the regulatory dose limits for workers [1]. The practical measures that need to be taken in order to reach these goals differ principally for the two types of radiation exposure: through external radiation and internal contamination.

\subsubsection{MEASURES AGAINST EXTERNAL EXPOSURE}

The presence of NORM in installations is unlikely to cause external exposures approaching or exceeding annual dose limits for workers. External dose rates from 
NORM encountered in practice are usually so low that protective measures are not needed. In exceptional cases where there are significant but localized dose rates, the following basic rules can be applied to minimize any external exposure and its contribution to total dose:

(a) Minimizing the duration of any necessary external exposure;

(b) Ensuring that optimum distances be maintained between any accumulation of NORM (installation part) and potentially exposed people;

(c) Maintaining shielding material between the NORM and potentially exposed people.

The first two measures, in practice, involve the designation of supervised or controlled areas to which access is limited or excluded. The use of shielding material is an effective means of reducing dose rates around radiation sources but it is not likely that it can be added to shield a bulk accumulation of NORM. However, the principle may be applied by ensuring that NORM remains enclosed within (and behind) the thick steel wall(s) of plant or equipment such as a vessel for as long as feasible while preparations are made for the disposal of the material. If large amounts of NORM waste of high specific activity are stored, some forms of localized shielding with lower activity wastes or materials may be required to reduce gamma dose rates on the exterior of the waste storage facility to acceptably low levels.

\subsubsection{MEASURES AGAINST INTERNAL EXPOSURE}

In the absence of suitable control measures, internal exposure may result from the ingestion or inhalation of NORM while working with uncontained material or as a consequence of the uncontrolled dispersal of radioactive contamination. The risk of ingesting or inhaling any radioactive contamination present is minimized by complying with the following basic rules whereby workers:

(a) Use protective clothing in the correct manner to reduce the risk of transferring contamination [17];

(b) Refrain from smoking, drinking, eating, chewing (e.g. gum), applying cosmetics (including medical or barrier creams, etc.), licking labels, or any other actions that increase the risk of transferring radioactive materials to the face during work;

(c) Use suitable respiratory protective equipment as appropriate to prevent inhalation of any likely airborne radioactive contamination [17];

(d) Apply, where practicable, only those work methods that keep NORM contamination wet or that confine it to prevent airborne contamination;

(e) Implement good housekeeping practices to prevent the spread of NORM contamination; 
(f) Observe industrial hygiene rules such as careful washing of protective clothing and hands after finishing the work.

\section{CONCLUSIONS}

- It has long been recognized that large doses of ionizing radiation can damage human tissues. Over the years, as more was learned, scientists became increasingly concerned about the potentially damaging effects of exposure to large doses of radiation. The need to regulate exposure to radiation prompted the formation of a number of expert bodies to consider what is needed to be done. The ICRP and the IAEA recommend the individual dose must be kept as low as reasonably achievable. We all face risks in everyday life. It is impossible to eliminate them all, but it is possible to reduce them. The use of coal, oil, and nuclear energy for electricity production, for example, is associated with some sort of risk to health. However, any increased level of radiation above natural background will carry some risk of harm to health. [18]

- In the oil and gas industry radium-226 and lead-210 are deposited as scale in pipes and equipment. If the scale has an activity of $30,000 \mathrm{~Bq} / \mathrm{kg}$ it is 'contaminated'. This means that for Ra-226 scale (decay series of 9 progeny) the level of Ra-226 itself is $3300 \mathrm{~Bq} / \mathrm{kg}$. For Pb-210 scale (decay series of 3) the level is 10,000 $\mathrm{Bq} / \mathrm{kg}$. These figures refer to the scale, not the overall mass of pipes or other material. Published data show radionuclide concentrations in scale up to $300,000 \mathrm{~Bq} / \mathrm{kg}$ for $\mathrm{Pb}$ $210,250,000 \mathrm{~Bq} / \mathrm{kg}$ for Ra-226 and $100,000 \mathrm{~Bq} / \mathrm{kg}$ for Ra-228. [19]

- In the absence of suitable radiation protection measures, NORM in the oil and gas industry could cause external exposure during production owing to accumulations of gamma emitting radionuclides and internal exposures of workers and other persons, particularly during maintenance, the transport of waste and contaminated equipment, the decontamination of equipment, and the processing and disposal of waste. Exposures of a similar nature may also arise during the decommissioning of oil and gas production facilities and their associated waste management facilities.

- Internal exposure to NORM may result from the ingestion or inhalation of radionuclides. This may occur while working on or in open plant and equipment, handling waste materials and surface contaminated objects, and during the cleaning of contaminated equipment. Ingestion can also occur if precautions are not taken prior to eating, drinking, smoking.

- The removal of NORM-containing scales and sludge from plant and 
equipment, whether for production and safety reasons or during decommissioning, needs to be carried out with adequate radiation protection measures having been taken and with due regard for other relevant safety, waste management and environmental aspects.

The regulatory body needs to set down conditions for the Protection of workers, the public and the environment, Safe disposal of solid wastes, Discharge of contaminated water and Conditional or unconditional release of the decontaminated components. The common goal in all situations is to keep radiation doses as low as reasonably achievable, economic and social factors being taken into account (ALARA), and below the regulatory dose limits for workers.

\section{REFERENCES}

1. International Atomic Energy Agency (1999), International Labour Office, Occupational Radiation Protection, Safety Standards Series No. RS-G 1.1, IAEA, Vienna.

2. Food and Agriculture Organization of the United Nations (1996), International Atomic Energy Agency, International Labour Organization, Oecd Nuclear Energy Agency, Pan American Health Organization, World Health Organization, International Basic Safety Standards for Protection against lonizing Radiation and for the Safety of Radiation Sources, Safety Series No. 115, IAEA, Vienna.
3. International Atomic Energy Agency (1995), The Principles of Radioactive Waste Management, Safety Series No. 111-F, IAEA, Vienna.

4. Kinsey, R.R., et al. (1997), "The Nudat/Pcnudat program for nuclear data", Capture Gamma Ray Spectroscopy and Related Topics (Proc. 9th Int. Symp. Budapest, 1996), Springer Verlag, Heidelberg.

5. Jonkers, G., Hartog, F.A., Knaepen, A.A.I., Lancee, P.F.J. (1997), "Characterization of NORM in the oil and gas production (E\&P) industry", Radiological Problems with Natural Radioactivity in the Non-Nuclear Industry (Proc. Int. Symp. Amsterdam, 1997), Kema, Arnhem.

6. Eisenbud, M., and Gesell, T. (1997), Environmental Radioactivity, 4th edition, Academic press, USA.

7. Kolb, W.A., Wojcik, M. (1985), Enhanced radioactivity due to natural oil and gas production and related radiological problems, The Science of the Total Environment 45 77-84.

8. International Atomic Energy Agency (2000), Regulations for the Safe Transport of Radioactive Material, 1996 Edition (Rev.), Safety Standards Series No. TS-R1 (ST-1, Rev.), IAEA, Vienna.

9. Gesell, T.F. (1975), Occupational radiation exposure due to $222-\mathrm{Rn}$ in natural gas and natural gas products, Health Phys. 29 681687. 
10. Summerlin, J., Prichard, H.M. (1985), Radiological health implications of lead- 210 and polonium-210 accumulation in LPG refineries, Am. Ind. Hyg. Assoc. J. 46 202-205.

11. Bird, A.F., Rosser, H.R., Worrall, M.E., Mously, K.A., Fageeha, O.I. (2002), "Technologically enhanced naturally occurring radioactive material associated with sulfate reducing bacteria biofilms in a large seawater injection system", Health, Safety and Environment in Oil and Gas Exploration and Production (Proc. Int. Conf. Kuala Lumpur, 2002), Society of Petroleum Engineers, Richardson, TX.

12. Hen, J., Brunger, A., Peterson, B.K., Yuan, M.D., Renwick, J.P. (1995), “A novel scale inhibitor chemistry for downhole squeeze application in high water producing sea wells", Offshore Europe (Proc. Int. Conf. Aberdeen, 1995), Society of Petroleum Engineers, Richardson, TX.

13. Ford, W.G.F., Gadeken, L.L., Callahan, T.J., Jackson, D. (1996), Solvent removes downhole NORMcontaminated BaSO4 scale, Oil Gas J. 94 65-68.

14. Fielder, G.D. (1994), "Application and evaluation of scale dissolver treatments", Corrosion '94 (Proc.
Int. Ann. Conf. Baltimore, 1994), National Association of Corrosion Engineers, Houston, TX.

15. Van Weers, A.W., et al. (1997), Current Practice of Dealing with Natural Radioactivity from Oil and Gas Production in EU Member States, Rep. EU 17621, Office for Official Publications of the European Communities, Luxembourg.

16. Silk, T.J., Kendall, G.M., Phipps, A.W. (1995), Revised estimates of dose from ores and mineral sands, J. Radiol. Prot. 15 217-222.

17. International Atomic Energy Agency (2003), Personal Protective Equipment, Practical Radiation Technical Manual No. 5, IAEA, Vienna.

18. Mishra U.C. (2004), Environmental impact of coal industry and thermal power plants in India,J.Environ.Radioactivity Vol.72, p.35-40.

19. Cooper M.B. (2003), NORM in Australian Industries, report for Radiation

Health \& Safety Advisory Council. 